Bu makaleye atıfta bulunmak için/To cite this article:

BILGINER ERDOGAN, Ș. (2021). Görsel Kültürün Küresel Kültüre Dönüșmesinde Kitle İletișim Araçlarının Rolü. Atatürk Üniversitesi Sosyal Bilimler Enstitüsü Dergisi, 25 (3), 109-126.

\title{
Görsel Kültürün Küresel Kültüre Dönüşmesinde Kitle İletişim Araçlarının Rolü
}

\author{
Şeyma BILGINER ERDOĞAN (*)
}

Öz: Insanoğlu duyulart yoluyla elde ettiği bilgilerle bir yandan günlük yaşamını sürdürürken diğer yandan bu bilgilerle toplumsal bir kültürün oluşumuna katkıda bulunur. Bu kültürel süreçlere iletişimin insanlar arasında ilişsi kurmasını sağlayan basit bir eylem olması gibi, tarihsel süreç içerisinde teknolojik araçlar yardımıyla gerçekleştirilmesi ve çok farklı ileti yollarının kullanılması da dâhildir.

On dokuzuncu yüzyılda kitle iletişim araçlarının icadiyla hızlanan veri akışı, bu araçları toplumsal hayatta önemli bir noktaya taşımıştır. Toplumu bilgilendirici, haber verici, eğlendirici işlevleri bu araçların etkisini daha da artırmıştır. Bilhassa yirmi birinci yüzyılının iletişim çă̆ bilişim çă̆l, gösteri çağı şeklinde nitelendirilmesinde bu araçlar çok büyük rol oynamaktadır. Yine bu araçlar, görselin artan kullanımıyla yeni görme biçimlerinin ortaya çıkmasına ve görsel kültürün küresel kültüre dönüşmesini sağlamıștır.

Bu çalışmada görselin bir iletişim biçimi olarak kullanılması, görsel kültür kuramı üzerinden ele alınmıştır. Bu amaçla özellikle görsele dayalı kitle iletişim araçlarında görselin kullanılma biçimleri üzerinden nasıl bir kültür oluşturulduğu incelenmeye çalışılmıştır. Görselin anlatımı ve iletişimi güçlendirmesi yanında toplumların ve insanların bakış açılarını yönlendirdiğ i noktasına vurgu yapılmaktadır. Literatür taraması yapılan bu çalışmada, görselin, seyircinin zihinsel dünyasını etkilemesi ve iletișimin kurulması așamasında önem tașıdiğına dikkat çekilerek, bu süreçte kitle iletişim araçlarının rolü üzerinde durulmuştur.

Anahtar Kelimeler: Görsel, görsel kültür, toplum, iletișim, kitle iletișim araçları.

\section{The Role of Mass Media in Transforming Visual Culture to Global Culture}

Abstract: While human beings maintain their daily lives with the knowledge they have obtained through their senses, on the other hand, they contribute to the formation of a social culture with this knowledge. Along with the fact that communication is a simple action that enables people to establish relationships among themselves, the realization of communication with the help of technological tools within the historical process, and the use of many different ways of communication are also included in these cultural processes.

The data flow, which gained speed along with the invention of mass media in the nineteenth century, carried these tools to an important point in social life. Their informative, communicative and entertaining functions for the society further increased the effects of these tools. In particular, these tools play a major role in their description as the twenty-first century's communication age, information age, show age. These tools also enabled the emergence of new

\footnotetext{
*) Dr. Öğretim Üyesi, Atatürk Üniversitesi İletişim Fakültesi Radyo Tv ve Sinema Bölümü (eposta: bilginer.seyma@ atauni.edu.tr) (D) ORCID ID. https://orcid.org/0000-0003-0618-6160

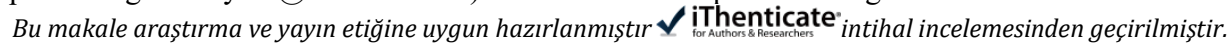


ways of seeing and the transformation of visual culture into global culture along with the increasing use of visuals.

In this study, the use of visual as a way of communication was discussed through visual culture theory. For this purpose, it was attempted to investigate how a culture was created through the ways visuals are used especially in visual-based mass media. It was emphasized that visuals strengthen expression and communication and also guides the perspectives of societies and people. In this study, whose literature was reviewed, it was pointed out that the visuals affect the audience's mental world and is of importance in the establishment of communication, and it was focused on the role of mass media in this process.

Keywords: Visual; visual culture; society; communication; mass media.

Makale Geliş Tarihi: 26.04.2021

Makale Kabul Tarihi: 23.09.2021

DOI: 10.53487/ataunisosbil.928525

\section{I.Giriş}

İnsan, dünyada var olduğu günden beri kendisi ve çevresiyle iletişimde bulunma zorunluluğundan dolayı çeşitli yollar denemiş ve bu yollar iletişimin farklı biçimlerde ortaya çıkmasını sağlamıştır. Kimi zaman bir şiir veya destan, kimi zaman yazının damgasını taşıan kitap, kimi zaman ikonik bir resim veya fresk, kimi zaman da mekanik bir aracın kanal olduğu fotoğraf, film, video gibi görsel araçlar yoluyla gerçekleştirilen iletişim, kendi tarihi içerisinde sözlü, yazılı, basılı, elektronik olarak adlandırılmıştır.

Görsel, elektronik devrimle başlayan ve son yüzyılda iletişimin vazgeçilmez bir formu olarak eski dönemlere oranla daha fazla tercih edilmektedir. Bir iletişim biçimi olarak görsel, yazı ve söz gibi etkileşim sağlayarak bir kültür üretme kabiliyetine sahiptir. Görüntülü bilginin yaygın kullanımı ile yazılı kültürün bireyselliğinin yerini tekrar kitleselliğe bıraktığ 1 düşüncesinden hareketle bu çağ "ikincil sözlü kültür çağı" (Ong, 2012) olarak adlandırılır. Başka bir ifadeyle bu çağ, birincil sözlü kültür geleneğinde var olan katılımcı yapıda olduğu gibi, topluluk duygusunun ön plana çıkması, görüntülerin sözle desteklendiği ve sözlü geleneğin yeni biçimi şeklinde değerlendirilmektedir.

Teknoloji yardımıyla hemen her kesime ulaşan bilgi, form değiştirirken, aynı zamanda mekân ve zaman kavramlarının yeniden tanımlanmasına, görmenin nitelik değiştirmesine de neden olmuş ve bir kültür haline dönüşmüştür. "Yeni olan bu görsel kültür, görsel olmayan şeyleri de görselleştirerek, nesnelerin yerine geçebildiği ve sayısız kez yeniden üretilebilerek, insan deneyimini her zamankinden fazla görselleştirmiş; sanat tarihi, film, sosyoloji, medya çalışmaları gibi alanlarda artan şekilde çalışılmalar yapılmasını sağlamıştır" (Mirzoeff, 1998:5-7). Görselin içerdiği kültür, görüntülerin bireyler üzerinde oluşturduğu etkiyle yerel ve küresel olanı da deneyimlemelerini sağlamaktadır.

Kitle iletişim araçları, ürettiği ürünlerle kültür oluşumunu sağlarken diğer yandan bu kültürün oluşumuna herkesi dâhil ederek, karşılıklı bir etkileşim yaratır. Özellikle "İnteraktif bilgisayar ağları, yeni iletişim biçimleri ve kanalları hayatı şekillendirerek, 
Görsel Kültürün Küresel Kültüre Dönüşmesinde Kitle İletișim Araçlarının Rolü

aynı zamanda hayat tarafından şekillendirilip katlanarak büyümeyi sağlar” (Castells, 2003:3). Yirminci yüzyılda kitle iletișim araçlarında görselin artan kullanımı, yine bu araçlar yardımıyla ulusal sınırları aşarak küresel bir kültürün oluşmasına katkıda bulunmaktadır. Bu ise McLuhan'ın ifade ettiği “küresel köy”e özgü gerçekliğin ortaya çıkmasıdır.

Bu küresel köyün kullandığı dil ise, kitle iletişim araçlarının gelişen teknolojik alt yapısına bağlı olarak kendine özgü ve evrensel sayılabilecek görsel ile güçlü bir yapıya ulaşmıştır. Bu çalışmanın amacı da kitlesel iletişimi gerçekleştiren araçların, görseli etkili bir şekilde kullanması, bu araçların gerçeklik ve toplumsal algı üzerinde etkin olduğu noktasına işaret etmektir.

Görsel kültür üzerine yapılan çalışmaların artması, özellikle modern dönemde göz kültünün ön plana çıkmasına bağlı olarak daha da hızlanmıştır. Dolayısıyla çalışmalar, sanatsal alanla birlikte 19 ve 20. yüzyılın önemli devrimlerinden olan kitle iletişim araçlarıyla daha farklı bir boyutta ele alınmaya başlanmıştır. Bu bağlamda Mitchell ve Mirzoeff gibi görsel kültür konusunda öne çıkan isimlerin sıklıkla duyulması, görsel kültürün tarihsel süreç içerisinde işaret ettiği noktaya bir dönemeç olarak bakmalarından kaynaklanmaktadır.

Görsel kültür konusunun medya ile olan ilişkisi, son yıllarda göze çarpan konular arasında olmakla birlikte, azımsanmayacak sayıda yapılmış farklı çalışmalarla literatüre kazandırılmıştır. Hüseyin Gençalp 2019 yılında yapmış olduğu "Görsel Kültür, Çoklu Okuryazarlık ve Çoklu Biçimlilik Bağlamında Sosyal Medya İletileri” çalışmasında insanların bilgiye ulaşırken, başvurdukları çoklu biçimli metinlerin yapılarını irdeleyerek, bu içeriklerin anlam üretme süreçleri üzerinde durmaya çalışmıştır.

Görselin yoğun şekilde bir iletişim biçimi olarak kullanılmasına bağlı olarak, okuryazarlık gerektiren ve ihmal edilmeyecek bir alan vurgusuyla yapılan bazı çalışmalar da vardır. Onlardan biri, 2017'deki "Görsel Kültür ve Görsel Okuryazarlık" başlıklı çalışması ile Sibel Onursoy'un, bilginin ve onun yayılma biçimlerinde ortaya çıkan materyal, kültürel, çevresel, bilgisayar, işitsel ve medya okuryazarlığ gibi, görsel okuryazarlık kavramının görsel kültürle olan ilişkisini, literatüre bağlı olarak incelediği çalışmasıdır.

Karin Becker, 2014'te "Where is Visual Culture in Contemporary Theories of Media and Communication?" başlıklı çalışmasında, önce görsel kültür alanındaki merkezi kavramları ve teorik ilkeleri detaylandırarak, bu alanda bir boşluk olduğuna vurgu yapmış, çalışmasını hem tarihsel olarak hem de mevcut medya ortamında görüntülenen medya ve iletişimin eleştirel yansıtıcı analizine nasıl katkıda bulunabileceği önerisiyle gerçekleştirmiştir.

Yine 2014'te "Researching Social Media and Visual Culture" başlıklı çalışma ile Liam French, sosyal medya kültüründe "görsel"e artan vurgu ile yeni ortaya çıkan görsellik biçimlerinin, geleneksel olanın sınırlarını bulanıklaştırma yollarını değerlendirmiştir. 
2004’te “İmgenin Gücü ve Görsel Kültürün Yükseliş̧” başlıklı çalışmasında Alev Fatoş Parsa, görselin, teknolojinin hızla gelişmesiyle, dünyanın "imgelerin ve görsel kültürün" kendine özgü kurallarıyla açıklanabilecek şekilde akıp giden bir sürecin içine girdiği noktasına vurgu yapmaktadır.

Tez çalışması olarak literatürde yer alan 2012 yılında "Şiddeti Görünür ve Meşru Kılan Görsel Kültürün Antropolojisi: Arka Sokaklar Dizisi Örneği” ile Hülya Doğan', 2007'de "Görsel Kültürde Bir Tüketim Nesnesi Olarak Beden: Video Klipler Örneği”" ile Oktay Işıkdoğan, görsel kültürü tüketim toplumu bağlamında ele almıştır. 2005 yılında Mustafa Mencütekin'in "Karizmanın Görsel Kültürde Sunumu: Gandi, Atatürk, Musa ve Hitler Örnekleri” ile karizmatik kişiliğin, hitabet ve kitleleri etkileme gücünün görsel kültür boyutunda sunumunu içeren ve Afitap Boz'un 2001'de "Bir İmge Üretme Biçimi Olarak Fotoğraf ve Görsel Temsil" çalışmasında imgenin tarihsel dönüşümü ve kültürel alanın görsel olarak tanımlanmasına neden olan değişmeyi konu alan tez örnekleri, alan yazına katkıda bulunan diğer çalışmalardır.

20. yüzyıldan beri, kültürden bilime, toplumsal yaşamdan eğitime, hayatın hemen her alanında etkili bir iletişim biçimi olarak kullanılan görsel, bir kültür olarak yükseliş sürecine girmiştir. Bu yükselişin özellikle 21. yüzyılda kitle iletişim araçlarının etkisi bağlı olarak daha hızlı ivme kazanması ve toplumsal alanda etkilerini göstermesi ise çalışmanın oluşumuna kaynak teşkil etmektedir.

\section{Görsel Kültür Nedir?}

Görsel kültürü tanımlamadan önce neden bir kültür olarak değerlendirildiği noktasına bakmak, çalışmanın amacını ortaya koyması bakımından önemlidir. Bunun yanı sıra görseli, bugüne dek geldiği süreç içerisinde ele almak yine bu amaca katkı sağlayacağından dolayı, bu kültürün temellerini insanın yeryüzünde var olduğu tarihe kadar geri götürmeyi de zorunlu kılmaktadır.

İlk olarak insanoğlu, hayatını devam ettirebilmek için basit aletler üreterek, bir yandan doğayı keşfetmek diğer yandan onu hâkimiyeti altına almak için çeşitli ve farklı buluşlarla, icatlarla, birikimiyle bir kültürün oluşmasına bilinçli veya bilinçsiz olarak katkı sağlamıştır. $\mathrm{Bu}$ kültürün aktarılmasında ise çeşitli iletişim kanallarının kullanılması sonucu, insanların kendilerini en iyi şekilde anlatabileceği farklı iletişim biçimlerinin ortaya çıkması söz konusu olmuştur. Tarihsel süreç içerisinde ilk olarak görsel iletişimin, insanlar tarafından Lascaux'taki mağara duvarlarına çizilen resimlerle başladığı ve zaman içerisinde fotoğraf, sinema filmleri, televizyon vb. araçlardan yayılan görüntülerle çeşitli şekillerde karşımıza çıktı̆̆ı görülür. Kullanılan bu iletişim biçimleri veya formları, ortaya çıktığı dönemin tarihsel ve toplumsal koşullarını göz ardı etmeden ele alındığında bir kültür taşıyıcısı olmaları yanında kimi zaman da kültür üreticisi konumunda oldukları görülür.

Görsellere dayalı olmasından dolayı görsel kültür olarak tanımlanan kavram ile ilgili ortaya net bir tanım koyulamamıştır. Çünkü görsel kültür kimine göre bakılan ve görülen şey, kimine göre görüntüler, kimine göre görsellik, kimine göre materyalist bir 
Görsel Kültürün Küresel Kültüre Dönüşmesinde Kitle İletişim Araçlarının Rolü

sanat analizi, kimine göre görsel deneyimlerin yorumu, kimine göre de tarihsel süreçler içerisinde insan faaliyetleri sonucu ortaya çıkan görsel eserler olarak nitelendirilen baskı ve resimler olarak tanımlanmıştır (Henderson 1999: 26). Bu nedenle görsel kültür, farklı kaynaklardan beslenen bir birikim sürecini de ifade etmektedir.

Duncum ise görsel kültürün sadece görsellikten ibaret veya tüketim kültürü olmadığını dile getirerek, görsel kültür alanının öncelikle doğa ve bilimsel ve en iyi ihtimalle marjinal sanat eğitimcilerinin ilgisini çeken mikroskobik, topoğrafi, rüya gibi birçok alanı kapsadığını savunur (2005: 154-155). Görsel kültürü, ideolojik ve politik olarak üretilen ve tüketilen, yeri geldiğinde toplumun geleneksel törenleri için kullandığ1 öğeleri kapsayan; bu kültürün ortaya çıkmasında onun bir iletişim biçimi olarak kullanılması, sanatsal bir faaliyet alanında yer alması, insanlar tarafindan üretilen bir metin, mesaj, kod ve yine üretilen bu görsel metinlerin yorumlanmas1 noktasında görsele dayanan her şey olarak tanımlamak mümkündür.

Başka bir eserinde Duncum, görsel kültürün net şekilde yapılamayan tanımıyla ilgili olarak yapılan herhangi bir tanıma itiraz edilebileceği noktasına vurgu yapar. Çünkü rizomatik olarak tanımladığı görsel kültürü, sürekli ve durmaksızın büyüyen karmaşık bir yer altı sistemi gibi düşünür ve tıpkı fare yuvası ve karınca kolonilerine benzettiği interneti değişim ve büyümenin somut bir örneği olarak gösterir (2001: 103). Bu değişim ve büyüme de görselin bir kültür haline gelmesinde etkilidir.

Görsel kültür alanında bir başka düşünce de sadece tasarım ve estetik bağlamlarıyla ilişkili düşünmek gerekmediğini söyleyen Tavin ve Housman aittir. Onlara göre görsellik kavramına baktığımızda, bu kavramın sürekli olarak görüntü üreten sistemler ve teknoloji sayesinde değiştiğini görürüz. Bunu sağlayan en önemli unsurlar ise medya ve medya teknolojileridir (Tavin ve Housman 2004: 211). Büyük ölçüde medya üretimlerine bağlı olan görsel kültür, sanat alanındaki eğitimleri de bu medya üretimleriyle birlikte ele almayı gerektirir.

Topluma ait ürünleri, eserleri, kültürü destekleyen veya besleyen görsellik, yine ait olduğu toplumun kültürel göstergeleriyle ifade edildiğinde ortaya çıkarmak istediği anlam veya mesajı doğru biçimde aktarır. Bundan dolayıdır ki "Görselliğe dayalı kültür, genel anlamda içinde yaşadığı tarihsel dönem ve toplumsal form dışında da ele alınamaz" (Çakır, 2014: 15). Aynı zamanda bağlamından koparılmış bir kültürel nesne, öğe, ürün veya eser vb. şeyler sadece görsel kültür üzerinden anlamlandırılmamalıdır. Buna ilaveten toplumun tüm yönlerini kapsayacak şekilde, bir kültür bazında değerlendirme yapıldığında daha anlamlı ve doğru sonuca ulaştırması mümkün olacaktır.

Görsel kültür, özellikle 19. yüzyılda hareketsiz görüntü olan fotoğrafın açtığı çı̆̆ır ve sonrasındaki süreçte devinim kazanarak hareketlenen görüntünün yeni bir kültür olarak tanımlanması noktasında da karşımıza çıkar. Bu yeni kültür ise evrensel bir dil oluşturarak, görüntülerle ortaya çıkan mesajları kimi zaman iletişim, kimi zaman tüketim, kimi zaman bilgi, kimi zaman haber, kimi zaman eğlence vb. içeriklerle dolaşıma sokmaktadır. 
$\mathrm{Bu}$ yeni görsel kültüre olan güven, geçmişten beslenen kaynakların yanı sıra özellikle 19. yüzyılda değişen sosyoloji ve felsefi düşünceler sayesinde yerini daha da sağlamlaştırmıştır. Bilimsel bilgiye olan güven artışı, görülmeyen şeylerin görülmesi veya görselleştirilerek sunulması, görselin bir kültür haline gelmesine ya da görselin yeni bir kültür yaratmasına ortam hazırlamıştır. "Her geçen gün ilerleyen teknoloji, Röntgen'in X-ray'le başlayan tesadüfî keşfi, Hubble sayesinde insan gözünün görmeyeceği kadar uzak galaksilere ulaşabilir olması" (Mirzoeff, 1998: 5) artık dünyanın eskisinden farklı ve yepyeni bir kültürle tanışması anlamını taşımaktadır.

Görsel kültürün net bir tanımı yapılamasa bile dil, din, ırk, kültürel yapı, yaşam biçimlerine etki etmesi yanında teknolojik alt yapının her geçen gün sunduğu imkânlarla, gözün egemen yapısının uzantısı olan "gözetim kültürü" nü ortaya çıkarması gibi, toplumsal yaşamı etkileyen birçok alanda farklı kültürlerin oluşmasına kaynaklık ettiğini söylemek de mümkündür. Görsel kültürde önemli olan nokta, görselden yola çıkarak görselin kendinden ziyade, birey, toplum ve dünyada ne anlamlar içerdiği, ürettiği ve tüketimi noktasıdır. Bu bağlamda görsel kültür anlamların oluşturulmasında ve sorgulamasında etkilidir.

\section{Görsel İletişim Nedir?}

İnsanların ve toplumların hayatında önemli işleve sahip olan iletişim, karşılıklı anlaşmayı, bireyin kendini ifade etmesini sağlayan ve sürekli olarak devam eden bir süreci ifade eder. $\mathrm{Bu}$ süreç farklı biçimlerde, farklı iletişim kanallarını veya araçlarını kullanmasından dolayı çeşitlilik göstermektedir. Bundan dolayı iletişim sözlü, sözsüz, yazılı, elektronik, dijital, görsel gibi kullanılan mesaj ve ortamlara göre farklı isimlerle anılmaktadır.

İletişim araçları veya ortamları, kullanıldıkları dönemlerde toplumun hemen her alanını etkilediğinden dolayı zaman içerisinde bir kültür oluşturmuş̧ur. Örneğin, insanların belleklerini aktif şekilde kullandıkları dönemde sözün, belleğin unutuşuna karşı panzehir olarak görülen yazının, matbaanın icadıyla baskının, elektronik devrimle bilgisayar ve internetin, toplumsal yaşam biçimlerinde, öğrenmede ve kültürel süreçleri etkilemede önemli olduğu ve bunların bir kültür oluşturduğu net olarak görülmektedir.

Diğer iletişim kurma biçimlerinde olduğu gibi iletişim sürecinde görselin de önemi çok büyüktür. Hatta görselin, yazı ve sözün bir adım önüne geçtiği söylenebilir. Şöyle ki, bir dildeki sözleri veya yazıları o dili bilmeden anlamak mümkün olamayacağı için iletişimde kazalara sebep olması veya iletişim kuramama gibi güç durumlarla karşılaşma olasıllğı söz konusudur. Bu durumda görselin daha evrensel veya daha anlaşılır olmasından veya ortaya çıkacak riskleri en aza indirmesi ihtimalinden ötürü, iletişimde öncelikli tercih sebebi olabilir. Mesela restoran yemek menüleri, tanıtım broşürleri, tarihi mekânların fotoğrafları, reklamlarda kullanılan ürünler ve daha birçok sayılabilecek örnek, iletişimi kolaylaştırması ve anlaşılır kılması bakımından görselin daha fazla kullanıldığ yerler olarak karşımıza çıkmaktadır. Hatta siyasi kampanya reklamları sözü güçlendirmek veya sözün etkisini artırmak için sıklıkla görsel metinlere başvurulan bir alandır. 
Görsel Kültürün Küresel Kültüre Dönüşmesinde Kitle İletişim Araçlarının Rolü

Bütün bu örneklerden yola çıkarak görsel iletişim nedir? diye sorduğumuzda, simge, işaret, resim, fotoğraf vb. gibi göz duyusuna hitap eden içeriklerle oluşturulmuş bir iletişim biçimi olarak cevaplandırılabilir.

Etkin bir iletişim sürecinin parçası olarak görsel kullanımı, İlkçağ mağara resimlerinde insanlar arasında basit bir iletişim eylemi olarak değerlendirilebileceği gibi, Rönesans Dönemi'nde ressamların ortaya koydukları sanat eserlerinde farklı rollerde kendini gösteren bir iletişim aracı olarak karşımıza çıkabilir. Örneğin; "Sandro Boticelli'nin (1445-1510) Roma'daki Sistine Şapeli'nde bulunan "Korah'1n Cezalandırılışı" adlı duvar resmi, Musa Peygamberin otoritesine başkaldıran bir adamı yutmak için açılan yeryüzünü betimler. 15. Yüzyılın sonlarında, kilisenin, Papa'nın iktidarını sınırlamak için toplantıya çağırması üzerine Papa IV. Sixtus tarafından aynı resmin sipariş verilmesi, Papa'nın Musa Peygamber olduğunu ve ayaklanmanın yararı olmadığı noktasına özellikle vurgu yapan sert içeriğiyle” (Briggs ve Burke, 2011: 47) görsel üzerinden karşıya net bir mesaj verilmek istenmektedir.

İletişim sürecinde mesajın hedef kitlenin dikkatini çekmesi ve etkisinin uzun süre devam etmesini sağlamak amaciyla bir yöntem olarak tercih edilen görseller, aktarılmak istenen düşünceyi, fikri veya mesajı, semboller, imgeler, simgeler ve metaforlar aracılığıyla gerçekleştirmektedir. Diğer iletişim biçimlerine göre yani sözlü veya yazılı vb. aktarıma göre daha kolay olan görsel iletişim, bu avantajından dolayı sıklıkla tercih edilmektedir. Çünkü yeri geldiğinde soyut bir kavramı görsele dönüştürerek yaşanabilecek iletişim aksaklıklarını ortadan kaldırabilmesi gibi nedenler, bu iletişim türüne olan eğilimi artırmıştır. Ayrıca görsel iletişim, diğer iletişim biçimleri olan sözlü, sözsüz, yazılı iletişim içeriklerini kendi sürecine dâhil edebilen yapısından dolayı çok yönlü bir süreci de ifade eder. Bundan dolayı bir kültürü, görsel kültür olarak tanımlamaktansa diğer tüm kültürlerin de görsel bir yönü olduğunu unutmamak gerekir.

Görsellik sadece sanat veya estetik kaygılarla oluşturulmuş kültürel ürünler değil, gündelik yaşamın bir parçası olarak etkili iletişim kurmanın yolu olarak yoğun şekilde kullanılmaktadır. Bu nedenle "görselleştirme dilsel söylemin yerini almaz, onu daha anlaşılır, daha hızlı ve daha etkili hale getirir. Görsel kültürün temel görevlerinden biri de, bu karmaşık resimlerin nasıl bir araya geldiğini anlamaktır” (Mirzoeff, 1998: 7).

Görsel iletişim, özellikle 21. yüzyılın iletişim, bilişim, sayısal, dijital, görsel vb. çağ şeklinde nitelendirilmesine bağlı olarak teknoloji desteğiyle iletişimi güçlü kılmak adına disiplinler arası bir çalışma alanı bulmaktadır. "Görme artık biyolojik olarak kabul edilmek yerine, genellikle kültürel süreçlerle oluşturulduğu düşünülen bir alan olarak değerlendirilmektedir. $\mathrm{Bu}$ şu anlama gelmektedir: Görmenin kendisi sorunsallaştırılmalıdır ve belirli görme biçimlerinin nasıl ve niçin oluşturulduğu sorgusunu yapmaktır" (Becker, 2004: 153).

Görsel iletişim, sadece görselin üretilmesi veya tüketilmesi bağlamında ele alınacak bir süreç olmanın ötesinde görselin, insanların günlük yaşam deneyimlerinde 
edindikleri bilgileri sorgulamada, bu bilgileri nasıl edindikleri hakkında, farklı alanlardaki ilişkileri sorgulama konusunda eleştirel okuma yapma imkânı da sunar.

\section{Görsel Nitelikli Kitle İletişim Araçlarının Kültür ve Toplumu Görselleştirmedeki Etkisi}

Son iki yüz yılda dünyadaki gelişmelere bakıldığında iletişim alanı, icatlar, buluşlar, keşifler, düşünce ve anlatı biçimlerinden beslenirken öte yandan yeni düşünce ve anlatı biçimlerinin eskilerinden farklı olarak gelişmesine neden olmuştur. Bilhassa iletişim alanındaki teknik imkânların elverişli hale gelmesi, kültürel yapıların ortaya çıkmasını sağlarken, var olan kültürel yapıları da ister istemez değiştirmiştir. Bu değişim her toplumda farklı şekillerde veya farklı etkilerle kendini göstermiş; özellikle on dokuzuncu yüzyılda sanayileşmenin getirdiği sonuçlar arasında hem felsefi hem toplumsal hem de ekonomi alandaki farklı düşünceler, kültürel dönüşümlerin yaşanmasına neden olmuştur. $\mathrm{Bu}$ dönüşümler insanın teknik alandaki bilgileri kullanabilme kabiliyeti ve bu kabiliyeti ilerletmesiyle kültürel çeşitliliği sağlayarak, farklı iletişim biçimlerinin yolunu da açmıştır.

Bu iletişim biçimlerinden biri olan görselin, fotoğrafla seri olarak üretime geçmesi ve hemen her alanda kullanılmaya başlaması veya rağbet görmesi, "semiyotik alanda etkiler bırakmıştır. Homojen toplumlarda görüntülerin arka planda bırakıldığ 1 okuryazar iletişim hâkimken, heterojen toplumlarda görüntü, tüm kesime ulaşmak için kültürel çeşitliliğe adapte olmak zorundadır. Bu durum ise ortak bir kültür anlayışı sağlamaktadır" (Duncum, 2005: 152-154). Ortaya çıkan bu yeni kültürel yap1 ise disiplinlerarası bir konu olarak gündelik yaşamın ayrılmaz bir parçası haline gelmiştir.

Görüntülerin yükselişte olduğu bu dönemi “"Resim Teorisi veya Resimsel Dönemeç" olarak adlandıran Mitchell bu kavramı, "kültürün yazıl kültür dönemecinden, imgeler aracıllğlyla görsel kültüre dönüş" olarak tanımlamaktadır (1994: 11). Bu dönemeç, görmenin önem kazandığı, görselin değişime uğradığı ve yükselişe geçtiği, "perspektif" e kadar uzanır. Perspektif, bireyi merkeze alması, bireyin kendi bakış açısıyla birlikte farklı bakış açılarından dünyayı yorumlayabilmesi, onu bilgiyi tekelden kurtarmasını ve kendisiyle ilgili karar alabilme yetisini sağlayan bir özne konumuna yükseltmesi bakımından önemlidir. Kartezyen bakış açısına sahip bu görme ve düşünme biçimleri, görselin veya imajın iktidarına yol açan, modern kapitalist sistemin devamlılığını sağlayan hâkim ekonomik ve kültürel yapılarla gözün yükselişe geçtiği bir gözetim sürecini de kapsamaktadır. Bu sayede ehlileştirilebilen dünya, aynı zamanda denetlenebilir hale gelmiş̧ir.

Yeni görme biçimlerinin ortaya çıkmasında etkili olan kitle iletişim araçları, aynı zamanda görsel kültürün küresel bir kültür haline gelmesinde de önemli bir unsurdur. On dokuzuncu yüzyıl, sanatta fotoğrafı, bilimde sosyolojiyi ortaya çıkarırken (Dora, 2003: 15), yaşanan bu kırılma, klasik görme biçimlerinin terk edilmesi ve buna bağlı olarak üretim ve zihinsel süreçleri değiştirmiştir. Aslında bu kırılmanın köklerini, sözün merkezde olduğu, asırlarca güçlü geleneksel yapının hüküm sürdüğü Antik Yunan'da gözün merkeze alınarak Paganik kültürün kendini göstermeye başlamasıyla 
görmek mümkündür. Sonraki süreçte ise Rönesans'la birlikte tekrar klasik eserlere dönüş, modern dünyanın temellerinin atarak, düşünce dünyasındaki yeniliklerle, değişen otoriteler ve bilimin gelişmesine giden yolun kapılarını açmıştır. Bu düşünceden yola çıkan Batı "gözü merkeze alarak teknoloji üretip, doğanın zorbalığına karşı insanın hâkimiyet alanını genişletip onu görünür kılar ve ona kimlik vererek" (Paglia, 2014: 119) toplumların görselleşme ve görme biçimlerine etki eder.

Kitle iletişim araçlarının yenilenen teknolojiyle her geçen gün insan hayatının ayrılmaz bir parçası haline gelmesi, iletişim tarihinde sözlü, yazılı, basılı, elektronik olarak nitelendirilen tüm bu süreçlere özgü kültürü yeniden üretmiştir. Son yüzyıl ise özellikle kitle iletişim araçları olan gazetelerde, dergilerde, fotoğraflarda, sinema ve televizyon ekranlarında, reklamlarda, video ve internette görüntülerin sürekli şekilde akması, görselin artan yükselişini hızlandırmakta ve toplumun görsel olarak düşünmesini, bakmasını ve buna bağlı olarak eylemde bulunmasını ve davranış geliştirmesini sağlamaktadır.

\section{A. Fotoğraf}

Fotoğrafın, resme öykünerek icat edilmesi ile ilgili tartışmalar bir yana, ortaya çıktığı yüzyılın felsefi düşüncesini ve bilimsel yaklaşımının bir yansıması olarak toplumsal ve kültürel boyutları dâhil ederek değerlendirmeyi gerektirmektedir. Bilimsel bilginin öne çıkışı ve teknik alanda yaşanan gelişmeler, sadece fotoğrafın ortaya çıkış serüveninde etkili olmakla kalmayıp, aynı zamanda görselin ve görmenin bir kültür oluşturucu öğe olmasına katkıda bulunmuştur.

Rönesans'ın öncülüğünde dinsel olanın dışında farklı konuların ele alınması, fotoğrafi kimi zaman portre gibi ticari bir metaya kimi zaman haberi destekleyen öğe olarak gazetede iletişim sürecinin bir parçası konumunda görmeyi gerektirmiştir.

Fotoğrafın ortaya çıkışıyla görme biçimlerinde yaşanan kırılma, sadece sanat ve teknik alanda çeşitlilik ortaya koymamış, gerçekliğin sorgulanması noktasında da tartışma yaratmıştır. Ortaya çıktığı on dokuzuncu yüzyılın en önemli buluşlarından biri olarak değerlendirilebilecek fotoğraf, görselin toplumlara ve kültürlere etki etmesi yanı sıra yeni medyaların ortaya çıkmasının yolunu da açmıştır. M.Ö. dördüncü yüzyılda ortaya çıkan Camera Obscura'nın öyküsü yirmi küsur asır sonra "fotoğrafla aracısız olarak, yeni bir görme biçimini, yani üç boyutlu görme biçimini iki boyuta indirerek" (Turan, 2011: 20), aynı zamanda görüntüye "kesinlik" kazandırmıştır. Gözün yükselişe geçtiği böyle bir ortamda sözü geride bırakan yapısıyla görsele olan inanç, fotoğrafin toplumda yaygınlaşmasını ve kültür oluşturmasını sağlamıştır. Modern olarak adlandırılan bu kültür, "görme ayrıcalığıyla elde edilen, iletişimin öncül olduğu ve yerden göğe kadar görülen bir olgudur” (Jenks, 1995: 2).

Toplumun görsel kaynaklara öncelik vermesinde fotoğrafın başat rol oynadığı görülmektedir. Fotoğrafin özellikle ortaya çıkışı ve yoğun talep görmesindeki nedenlere baktığımızda, o dönemde yeni bir toplumsal sınıf olarak beliren burjuva sınıfı karşımıza çıkar. Soyluların yaptırdığı gibi burjuva sınıfının da ressamlara portre 
tablolarını çizdirme arzusu, bir bakıma hem toplumda görünür olmanın hem de zenginliğin bir aracıdır. Fotoğraf, ortaya çıktığı dönem itibariyle sosyal statü, toplumsal sınıf aidiyeti gibi nedenlerden dolayı tercih edilirken diğer taraftan görsele artan rağbet sonucu, gerçeğe en yakın hatta gerçeğin bir formu olarak toplumun görselleşmesine neden olmuştur.

Fotoğrafın görsel aracılığıyla elde etmiş olduğu güç, inandırıcıllğı̆ını artırmış; kitle iletişim aracı olarak kullanılmasıyla da bu gücünü pekiştirmiştir. Yazılı basında sözü güçlendirmek ve olaya dikkat çekmek için kullanılan fotoğraf, aynı zamanda okurun dikkatini yönlendirme gücüne sahiptir. Bundan dolayı "fotoğraf, ortaya çıktığı tarih itibariyle toplumdaki egemen sınıfların ihtiyaç ve arzularını karşılamaya, toplumsal olayları bu sınıf gibi yorumlamaya en müsait araç olarak, birebir doğaya bağlı gibi görünse de sahte bir nesnelliği vardır. Bu sahte nesnellik ise görüntüyü elde eden kişinin görme biçimi ve ortaklarının isteklerine göre belirlenmesinden dolayıdır. $\mathrm{Bu}$ nedenle fotoğraf, düşüncelerimizi yönetmek ve davranışlarımız düzeltmek amacıyla başvurulacak etkili bir yöntemdir" (Freund, 2006: 9).

1842 yılında İngiliz basınında görülmeye başlayan fotoğrafın, gazeteler için pencere niteliği taşıyan ve ihtiyaç doğrultusunda kullanılan bir araç olduğu göze çarpar. Durdurulmuş pencere olan fotoğrafa bakan kişi, olaya bu pencereden bakar. Yazının reklamı ve gazetelerin vazgeçilmez öğesi olan fotoğraf, haberin inandırıcilığını kuvvetlendirirken, olayın doğruluğunu da kanıtlar, bazen de başlı başına bir haberdir. Fotoğraf öncesinde ise yine habere canlılık kazandırmak için gazetelerde ressamlar tarafindan çizilen ve illüstrasyon denilen resimler aracılı̆̆ıyla haberle ilgili görsel bilgilere rastlanır. Örneğin, Kırım Savaşı'nın resimleri, bu ressamlar tarafından aslına sadık kalınarak yapılmış eserlerdir (Bodur, 1990: 297- 298). Fotoğrafın basında kullanılması, insanların fotoğrafla birlikte dünyayı görmesine olanak sunmuş ve bu bakış ise dünyayı küçültmüştür. Soyut sözcükler yerine geçen somut fotoğraf, görsel medyanın temellerini atmıştır (Freund, 2006: 96).

Fotoğrafın basında alanında kullanıma girmesi, görselin artan yükselişine neden olmuş, toplum ise hem daha kolay okuma yöntemi olduğu için hem de inandırıcılığından dolayı görsele meyletmiştir. Bu sayede yaygınlığı artan fotoğrafın gücü, sanat alanıyla kısstlı kalmamış, diğer kitle iletişim araçlarıyla birlikte kullanılmasıyla birlikte icadından bugüne kadar geçen sürede varlığını tartışmasız sürdürme imkânını sağlamıştır.

\section{B. Hareketli Görüntü ve Televizyon}

Sinema filmlerinin yaygınlaştığı dönem olan yirminci yüzyılın ilk yarısı, kendinden önceki yüzyılda olduğu gibi yine toplumsal değişimlerin yaşandığı, var olan düşüncelerin sorgulandığı bir dönemdir. Aynı zamanda bilimsel ve teknolojik gelişmelerin hız kesmediği, toplumdaki yerleşmiş kalıpların, değerlerin ve kurumların sorgulandığı, gelişen teknolojik araçlara bağlı olarak zaman ve mekân kavramlarının yeniden biçimlendiği bir yapı söz konusudur. İletişim alanındaki yeniliklerin her geçen gün artan ilerlemesi, yeni siyasi sistemlerin kurulması, yeni ülkelerin ortaya çıkması, savaşların patlak vermesi sonucu değişen politik düşüncelere bağlı olarak nükleer 
Görsel Kültürün Küresel Kültüre Dönüşmesinde Kitle İletișim Araçlarının Rolü

silaha ve uzay alanındaki çalışmalara yönelim, sanatsal alanda da değişim ve dönüşümlerin yaşanmasına katkı sağlamıştır. Böyle bir ortamda geçmişten getirdiği birikimleri de ekleyerek, yeni arayışlarla var olan görüntüleri harekete geçiren sinema ortaya çıkmıştır.

Sinema sayesinde küçülen dünyada insanlar birbirlerine ne kadar benzediklerini veya ne kadar farklı olduklarını gördüler. Bunun yanı sıra filmler aracıllğıyla düşünce ve estetik duygunun dışa vurumu, kişisel ifade tarzlarının filmlerde kullanılması, sinemanın özgün bir dili olduğunu ortaya koymakla kalmamış, aynı zamanda sanatçıların yepyeni denemelerle, farklı yöntemler geliştirip, farklı konuların ortaya çıkmasını sağlamaları için de bir olanak sunmuş ve sunmaktadır (Abisel, 2007: 9).

Birbirine bağlı olarak ilerleyen teknoloji ürünlerinin bir alanda meydana getirdiği buluşlar veya yenilikler toplumda diğer tüm alanları da etkiler. Fotoğrafın hareketli hale getirilmesiyle sinemanın icat edilmesi, sanatsal alanda farklı akımları ortaya çıkarmakla kalmamış, birbiriyle ilgili olmadığı düşünülen alanlara da katkı sunmuştur. Örneğin; 1882'de Fransız bilim adamı fizyolog Etiene Jules Marey, geliştirdiği fotoğraf tüfeğini kuşların nasıl uçtuğunu incelemek üzere, yavaşlandırılmış-hızlandırılmış görüntü tekniğini kullanarak, daha sonra sinemada anlatımı güçlendiren bu yöntemle kuşların kanat çırpışları esnasında insan gözünün algılayamadığı anları açık seçik olarak görüntülemiştir. "Marey, "chronophotographie" adını verdiği bu buluşunun aynı zamanda kalp ve damar hastalıklarının teşhisinde nasıl yararlı olacağını açıklarken" (Abisel, 2007: 26), bu durumun aslında görselin her alanda kullanılmaya başlamasıyla, insanoğlunun gördüğü şeyin ne olduğunu bilmesine; dolayısıyla belirsizlik durumunun ortadan kalkmasıyla da gözünün gördüğü şeye olan güven hissini pekiştirmiştir.

Sinema ile dünyaya açılan göz, elde ettiği görüntülerle görsel temsil sunarken, düşüncelere bağlı olan bir görme biçimi ortaya koyar. Mesela ortaya çıktıkları ülkelerin isimleriyle anılan Fransız Yeni Dalga, İtalyan Yeni Gerçekçilik, Alman Dışavurumculuğu gibi akımlar, ortaya çıktıkları toprakların kültürel, siyasal, sosyal ve ekonomik yapılarına bağlı olarak filmler ortaya koymuşlardır. Birinci Dünya Savaşı sonrası bu ülkelerde yaşanan acı, sefalet, psikolojik yıkımın yansımaları olarak toplumun aynası olmanın yanı sıra gerek düşünce yapısı gerek tekniğin, mekânın kullanımı gibi sinematografik anlatım unsurlarıyla, toplumun görme biçimleri üzerinde etkili olmuşlardır. Veyahut Amerikan sinemasına baktığımızda Avrupa'ya göre kültürel gelişimini daha geç tamamlamış olmakla beraber, sinemaya ticari kaygı güdülerek yaklaşıldığı için kapitalist sistemin koşullarını yerine getirecek şekilde stüdyo içerisinde film yapıldığı görülür. Yine film karelerini birbiri ardınca sıralı ve öyküyü anlatacak şekilde bağlayan kurgu yöntemi, modern düşünme ve görme biçimini etkileyen, modern insanın hızlı şekilde düşünmesine benzer şekilde hızlı algı oluşturma gücüne sahiptir. Bu görme biçimleri ise bilimsel, ekonomik, endüstriyel, kültürel, siyasi değişmelerin sonucunda ve tesadüfî olmayan çalışmaların sonucuna bağlı olarak gelişmiştir. 
Yirminci yüzyılın ikinci yarısına imza atan bir diğer kitle iletişim aracı ise yine görsel iletişim sağlama gücü yüksek olan televizyondur. Sesle görüntüyü birleştiren televizyon, ilerleyen zamanla hemen her eve girerek, görselin yükselişe geçmesinde çok büyük etkiye sahiptir. Daha fazla kitleye anında ulaşılabilirlik hizmetini sunan bu araç, büyük oranlarda izleyici kitlesine her zaman ulaşmayı başarmış ve başarmaktadır.

Televizyon, gündelik yaşam içerisinde, boş zaman etkinliği olarak önemli bir kültürel aktarım aracı olarak değerlendirilebilir. Dünyadaki var olan kültürleri aktarması yanı sıra kültür üretme potansiyelini de unutmamak gerekir. Aslında televizyonu iletişimin tarihsel süreci içerisinde ele aldığımızda kendinden önceki tüm iletişim, haber alma, öğrenme veya eğlenme biçimlerini değiştirdiğini görürüz. Bu değişimi ise Raymond Williams, onun teknik imkânlarına bağlı olarak toplumsal değişime neden olduğu bazı durumları şu şekilde ele almıştır:

Bilimsel ve teknik araştırmalar sonucu icat edilen televizyon, sosyal bir iletişim aracı olarak geleneksel kurumların ve sosyal ilişki biçimlerinin çoğunu değiştirmiştir. Elektronik iletişim aracı olmasından dolayı insanların gerçeklik algıları yanı sıra aile yapılarına, sosyal yaşama etki ederek, bir eğlence ve haberleşme yolu olarak gelişmiştir. Yeni tip bir toplumun gereksinimlerini karşılamak için yatırım ve gelişme alanı olarak görülen televizyon, karakteristik ev araçlarından biri olarak yeni, karlı, eviçi tüketim ekonomisinde satış aracı olarak da görülmüştür. Ayrıca kültürel ve psikolojik bir yetersizlik olarak insanda daima bulunan pasiflik, televizyon tarafindan organize ve temsil edilir olmuştur. Yeni tip büyük ölçekli fakat atomize bir topluma bir taraftan hizmet ederken öte yandan onu sömürmektedir (Williams, 2003: 10-11).

Televizyonun satış aracı olarak görülmesinin bir nedeni de, görsel iletişimin başka bir aracı olan reklamların, televizyon yayınları aracılığıyla kitlesel tüketimi sağlamasıdır. İlk örnekleri Eski Mısır'da kaçan esirleri bulana ödül verileceği bilgisinin bulunduğu papirüslere çizilen reklamlar, bugün ise imgeler, imajlar, semboller aracılı̆̆ıyla toplumsal hayatta her biri bir șeye denk gelecek șekilde insanın zihninde sürekli tekrarlarla farkında bile olmadan bir algı oluşturmaktadır. Toplumun görselleşmesi, üretimin serileşmesine bağlı olarak tüketimin körüklenmesine veya insanları tüketim konusunda eyleme geçirecek etkili unsurların kullanılmasıyla kapitalizmin büyümesine katkı sağlamaktadır. Tüketime yönelen insanlar, tüketim toplumunun değerlisi olarak, gerçekmiş gibi verilen imajları satın alarak, bolluk içinde hür iradesiyle seçim yapan birey hissine kapılmaktadırlar. Bu his ise sahip olunan nesnelerle mevki, statü, saygınlık, aidiyet bağıyla kitlesel tüketimi sağlayıp, kitle toplumunun oluşmasına bilinçli veya bilinçsiz olarak katkıda bulunur. Kitle iletişim araçlarından sürekli maruz kalınan bu yoğun görüntü bombardımanı, toplumun görme biçimlerine ve bireylerin bu imajlar üzerinden kimlik oluşturma çabalarına etki eder. $\mathrm{Bu}$ davranış şekilleri ise yeni yaşam biçimlerinin ortaya çıkmasını sağlar.

Görselin en yoğun olarak kullanıldığı, hiç durmadan yenilenen, içinde bulunulan zamana uydurulan, geçmiş ve daima gelecekten söz eden ve anlık olan reklamlar, çekicilik üreterek insanlara satın almak için seçtikleri nesneler aracılı̆̆ıyla bir özgürlük alanı sunar. Reklam, onu izleyen veya kullananlara seçim hakkı sunduğu için onlara tükettikçe demokratik bir eylem gerçekleştirdikleri hissini verir. Tüm dünya 
Görsel Kültürün Küresel Kültüre Dönüşmesinde Kitle İletișim Araçlarının Rolü

reklamlarda sözü edilen güzel yaşamın gerçekleştirilebileceği yer olarak gösterilir ve dünyanın geri kalanını gözlerden siler. $\mathrm{Bu}$ ise reklamın her şeyi kendi diliyle açıklaması ve yorumlamasıdır (Berger, 2013: 145-149).

Modern olarak nitelendirilen kitle insanının görme biçimi, tıpkı kitle iletişim araçlarındaki sayısız şekilde akan görüntüler gibi sadece bakmaktan ibarettir. Görmek ile bakmak arasındaki farkı yakalamak gibi hızlı şekilde akan enformasyon arasından bilgiyi seçip almak çoğu kere mümkün olamamaktadır. Başka bir deyişle televizyonun sunduğu içerik üzerinde insanların konuşup, tartışmaları bile bir bakış açısı oluşturur ve insanlar çoğu kez bu durumun farkında dahi olmadan önceden belirlenmiş konu üzerine yoğunlaşarak düşünürler. Bunun temel nedenleri arasında televizyonun günlük yaşamda yoğun şekilde kullanılması gösterilebilir. McLuhan, "gündelik yaşamda kapsayıcı ve egemen role sahip kitle iletişim araçlarının her alanı istila ettiğini dile getirir ve iletici aracın mesaj olduğunu" (Oskay, 2000: 223) bir kez daha yineler. Bir iletişim aracı olmanın ötesinde yeni toplumsal yapılar üretmesi bağlamında televizyon, günlük yaşamın vazgeçilmez bir parçası olarak görsel ve işitseli birleştirerek, "kültürü yapısal dönüşüme uğratarak muazzam bir gösteri sahnesi yaratmıştır" (Postman, 2010: 93).

\section{C.İnternet}

Birçok bilgisayarı ve sistemlerini dünya çapında birbirine bağlayan internet, sürekli kullanılan yaygın bir iletişim ağı olarak tanımlanabilir. İlk olarak askeriye, üniversite, araştırma ve kütüphane bilgilerini depolamak için yapılan çalışmalarla ortaya çıkan ağ sistemi, ilerleyen süreçlerde sınırları belirlenemeyen, zaman ve mekân kavramlarını yeniden tanımlanmasının gerektiği küresel bir yapı haline gelmiştir. Daha çok 90'lı yıllardan sonra toplumsal hayata giren ve sonrasında ticari olarak internet ağının yaygın kullanımı, aslında dünyanın bugünkü kaderini oluşturan bir dönemeci de ifade etmektedir.

İnternet ile 1990'lı yıllarda (Web 1.0) yani “sadece arama” nın yapıldığı, interaktif iletişimin mümkün olmadığı, gazete, dergi ve kitap gibi sadece okunabilen; metin, resim, tablo, grafik gibi durağan içeriklerin kullanıldığı bir yapı söz konusudur. 2004 yılında ise Web 2.0 teknolojisiyle bilgininin kontrolünün internet kullanıcısına geçtiği, site ve blogların üretildiği aktif bir süreçten bahsetmek mümkündür. Bundan dolayıdır ki 2006'da Time Dergisi tarafından “yılın kişisi” unvanı sıradan internet kullanıcılarına layık görülmüştür (Özdemir ve Karalar, 2012: 102). Bununla yetinmeyen insanoğlu Web 3.0 teknolojisini yani "semantik web" i geliştirmeye çalışmakta ve hatta tanımı henüz net yapılamayan ancak gelecek için planlanan Web 4.0 ile karar alma ve zihin kontrol süreçlerinde makinenin kabiliyetini artırmayı amaçlamaktadır.

Bilgisayarın icadıyla verilerin sayısal olarak saklanması, fiziksel imkânsızlı̆̆ı ortadan kaldırırken aynı zamanda bu araçların, "bilgisayar aracılı̆̆ıyla iletişimin belkemiği olan internet sayesinde" (Castells, 2004: 463) kilometrelerce ötedeki coğrafyalar arasında bağ kurabilme kapasitesi ve kopyalama ile, hızlı şekilde verilerin en uzağa iletebilmesi mümkün olmuş ve bu araçların kurduğu ortamlar ise "yeni 
medya" olarak tanımlanmıştır. Bu yeni medya ortamlarının ortaya çıkmasını sağlayan "Teknolojik gelişmeler, görsel kültürdeki görselliği değiştirmiş, bu alana sayısallaşan ve dijitalleşen imgeyi de eklemiştir. Bu yeni teknoloji, uçsuz, bucaksız dünyada ulus aşırı imkânlara zemin hazırlayarak, görselliğe dayanan kültürü de fazlasıyla etkilemiştir" (Çakır, 2014: 16).

Görsel kültürde dijitalleşen dünya, zaman ve mekâna bağlı olmadan herkesin imge üretimine olanak tanır. Bu yanıyla dijital kültür, an'ın yakalandığı ve yeniden üretildiği fotoğraf ve kamera sonrası, an'ın yaratıldığı bir dönemi ifade eder, böylece kitle iletişim araçlarını kullanan kitle, dijital teknolojiyi kullanarak imge ve içerik üreten, üretilen içerikleri değiştiren, gerçekliğin üretiminde aktif rol alan bireylere dönüşmüştür (Bilginer Kucur, 2018: 33-34). Bu durumdan hareketle insanlar görseller aracılı̆̆ıyla ürettikleri ve dolaşıma soktukları ürünlerle, kültürel yaşamın ve kültürel üretimin bir parçası durumundadırlar ve bunu da kullanmakta oldukları kitle iletişim araçları yoluyla gerçekleştirmektedirler.

Bir güncel görme biçimi olarak adlandırabileceğimiz internet ve onun üretip dolaşıma soktuğu görüntüler, bakışı küreselleştirmiştir. "Bu sürecin yakından ilgili olduğu internet, tüm dünyayı kuşatıcı, birbiriyle iç içe geçen ağ sistemleri, küresel bakışa ve düşünce biçimlerine yaslanarak, aynı zamanda küresel davranmayı teşvik etmekte ve beklemektedir. Yerelle kalmak veya yerel yetinmek bir yetersizlik olarak, dünyayı algılayamama, değişimlerin dışında kalma, onları uygulayamama olarak dayatıldığı" (Çakır, 2014: 77) için gelişmemişliğin bir göstergesi olarak da nitelendirilebilmektedir. Kendi teknik özelliklerinden dolayı diğer araçlar gibi internet de kendine has ortam ve kültür üretir. Hayata bakış için algıları etkileyerek, bakış açılarını şekillendirir. Gündelik hayatın bir parçası veya tamamı olarak yeni yaşam biçimleri üreterek aynı zamanda onları pazarlar. Örneğin; internetin toplumsal alana girmesiyle reklamların, bilginin, mahremiyet alanlarının ihlali, yeni meslek gruplarının ortaya çıkması veya var olan mesleklerin fiziksel alana ihtiyaç duymadan sanal ortamlarda varlığını sürdürebilmesi, insanların sosyal ağlarda varlıklarını kanıtlamak veya kimliklerini tanımlamak için sürekli görüntü üretmesi ve daha sayılabilecek birçok şey yeni bir görme biçimi olarak tanımlanabilir. Bu görme biçimleri ise kültürel alana etki etmekte ve bir bakıma yeni bir kültür oluşturmaktadır. Bu verili ortama gözlerini açan insan ise sürekli akan görüntüler içerisinde tek tip görme biçimiyle dünyasını anlamlandırmaya çalışmaktadır.

Her gün çoğumuz farkında olmadan teknolojik araçlar aracılığıyla dünyayı anlamaya ve anlamlandırmaya çalışırız. Bu araçlardan yayılan mesajları algılarken, anlamlandırırken aslında her aracın kendine özgü iletişim dilinden ya da bakış açısından olayları veya nesneleri yorumlarız. Bu ise insanın dünya ile olan ilişkisini tümden değiştirmiştir. Örneğin, fotoğrafın veya kameranın sürekli ve çoğaltılabilir görüntü üretmesi, anlamları çoğaltırken asıl anlamların ortadan kaybolmasına neden olmuştur. Bugün de dijital teknoloji ile imajin çoğaldığı, herkesin görüntü ürettiği, ortaya çıkan görüntülerin sürekli araçlar arasında aktarıldığı bir ortamın varlığı söz konusudur. Görünmez olarak adlandırılan dijital devrim ile insanlar içinde yaşadıkları dünyanın farkında olmadan sürekli akan görüntü evreninde nadiren gerçeklik 
sorgusunu gerçekleştirmektedir. Berger'in (2013) ifadesiyle, sadece baktığımız şeyi görüyoruz. Oysaki bakmak bir seçim sonucunda ortaya çıkan eylemdir. Ve bu seçim yaşanılan zamanı anlayabilmek için hayati önem taşıyan bir görme biçimidir.

Sonuç olarak açıkça görme, ne kadar bildiğimiz ve nasıl anladığımızın bir bileşimidir. İzleyicinin zihinsel durumu, görsel iletişim sürecinde hayati bir bağlantıdır. Kitle iletişimi tarihinde daha önce hiç olmadığ kitaplarımızı, kıyafetlerimizi, reklam panolarını, gazetelerimizi, dolduruyor. Görme aracılı bir toplum haline geliyoruz. İsyankâr/asi gençlik görsel sembollere yapışır, çünkü kelimeler eski iletişim yollarıyla ilişkilidir ve sosyal düzeni tesis etmenin eski yolları olarak görülür (Lester, 1995: 415-417)

İletişim teknolojilerinin her geçen gün yeni imkânlar sunması veya dünyaya yeni kapılar aralaması, dünyada var olan kültürler arası ilişkide dengeyi bozmaktadır. Baskın kültürlerin diğer kültürler üzerinden söz sahibi olması, var olan sömürgenin dijital alana kaymasından başka bir anlam ifade etmemektedir. Nesnelerin, ilişkilerin, anlamın, gerçekliğin, zamanın, mekânın, kimliğin, benliğin yeniden tanımlandığı bu çağda nitelik yerine biçimsellik ve görsellik öne çıkmakta ve bu da hâkim kültür yapısının çok fazla sorgulanmasına imkân vermemektedir.

\section{IV.SONUÇ}

Mitchell, görselin hâkimiyetinin ve üstünlüğünün söz konusu olduğu dönemin başlangıcını "resimsel dönemeç" kavramıyla açıklarken, bir bakıma modern dönemin karakteristik özelliğini yansitan görmenin veya göz kültünün yükselişini ifade eder. Göz kültünün öne çıkması ise elektronik devrimle görselin seri şekilde üretilmesi sonucu kitlesel kültürün oluşumuna zemin hazırlamıştır.

Görmeye dayanan ve iletişim için birincil ortam olan görsellik, modern dünyayı da yerden göğe kadar görünen bir olgu yapar (Jenks, 1995: 2). Nesnelerin, ilişkilerin, anlamın, gerçekliğin, zamanın, mekânın, kimliğin, benliğin yeniden tanımlandığı bu çağda nitelik yerine biçimsellik ve görsellik öne çıkmakta, bu da hâkim kültürel yapının çok fazla sorgulanmasına imkân vermemektedir. Modern çağın simgelerinden olan alışveriş merkezleri, video oyunlar, sinemalar, gece kulüpleri, reklamlar, filmler, internet, sosyal medya ortamları, gözetim teknolojileri, moda gibi kavramlarla özellikle ortaya çıkan görsellik, gündelik yaşamın ayrılmaz bir parçası olarak insan hayatını ve toplumdaki kültürü etkiler, bunu da kendine özgü bir dille gerçekleştirir.

Bir iletişim tarihi, iletişimin gerçekleştiği dilsel aracı ihmal edemez (Briggs ve Burke, 2011: 44) Dilsel araç, kimi zaman sözle, kimi zaman yazıyla, kimi zaman bir firça darbesiyle, bazen bir heykelin duruşuyla, bazen bir fotoğraf veya filmle, bazen de insan zihnine yön veren akıllı olarak adlandırılan bir araçla toplumsal, dinsel, siyasi, kültürel duygu ve düşüncelerin aktarıldığı bir yol olabilir. $\mathrm{Bu}$ nedenle aracın kullanıldığı döneme göre değerlendirilmesi, verilmek istenen mesajı anlamayı kolaylaştırır. 
Görsellik her ne kadar modern dönemde daha çok öne çıkmış gibi görünse de bu durum görselliğin başka bir dönemde kullanılmadığı anlamına gelmez. Bu sadece modern dönemde bilimsel ve sosyolojik zeminin değişmesiyle birlikte görünmeyenin görünür olmasına ve gözün gördüğüne olan inançtan kaynaklanır. Yeni bir kültür oluşumunu sağlayan bu bakış açısı veya görme biçimi, görselin tüm toplumsal alanı; ekonomi, kültür, siyaset, bilim, yönetim biçimleri, değişen devlet yapıları vs. etkileyerek yeni toplumsal sınıfların ortaya çıkmasında veya var olan sınıfların görünürlüğünü artırmada önemli rol oynar. Görmenin yönetim alanında iktidarı güçlendiren bir araç olarak gözetimi güçlendirmesi, kapitalist sermayenin bu alanlara yatırımıyla küresel sermaye piyasasını elinde tutma isteği, sömürgenin bir başka türü olan kültürel emperyalizmin ortaya çıkışı gibi sayılabilecek daha pek çok durum, kitle iletişim araçlarının ulus aşırı coğrafyalara ulaşmasını sağlayan gücüyle daha da kolaylaşmıştır.

Görseli basitçe kitle kültürü veya bilginin aracı olarak görmek yanlıştır. Ancak görsel, basılı medyanın boy ölçüşemeyeceği kadar bedensel dolaysızlık sunar: Her türlü farklı metinlerden 1lımlı görüntüler yapar. Görsel kültür, günlük yaşam içerisinde aşırı görsel ve bilginin krizidir (Mirzoeff, 1999: 7). Bugün içerisinde yaşanılan toplumda görmeye dayalı bir yapıdan kopuşun mümkün olmadığı görülmektedir. Bilhassa kitle iletişim araçlarının icadıyla başlayan süreç, sürekli akan görüntü bombardımanı karşısında insanı, bakan ama görmeyen bir konuma itmiş̧tir. Varlı̆̆ çoğunlukla görmek ve görülmek üzerinden değerlendirilen pasifize edilmiş birey, özellikle teknolojilerin sağladığı olanaklar neticesinde, gönüllü veya farkına varmadan etki altına alınarak, yeni bir toplum kültürünün oluşumundan bihaberdir. Bu noktada toplumu görselden veya görseli toplumdan soyutlamak mümkün olamayacağından, görselin dilini öğrenmeye çalışmak gerekmektedir. Bunun için de verilmek istenen ideoloji, mesaj, aşılanmak istenen düşünce, zihinlerin yönelendirilip-yönlendirilmediğinin ayırdına varacak şekilde eleştirel bir gözle okuma yapmaya ihtiyaç vardır. Bu ihtiyacı karşılamak için ise medya okur yazarlığı genelinde veya görsel olur yazarlık özelinde, öğretim kademelerinin çeşitli dönemlerinde bu konuda eğitimlerin verilmesi, bireyin en azından farkındalığını sağlaması bakımından önem taşımaktadır.

\section{Kaynaklar}

Abisel, N. (2007). Sessiz Sinema. Deki Basım Yayım.

Becker, K. (2004). Where Is Visual Culture In Contemporary Theories Of Media And Communication? Nordicom Review, 40 (2). 149-157. https://content.sciendo.com/view/journals/nor/nor-overview.xml

Berger, J. (2013). Görme Biçimleri. (Çev. Yurdanur Salman). Metis Yayınları.

Bilginer, Kucur, A. (2018). Transmedya Hikâye Anlatıcllı̆gl: Angry Birds Evreni Örneği. Arı Sanat Yayınevi. 
Görsel Kültürün Küresel Kültüre Dönüşmesinde Kitle İletişim Araçlarının Rolü

Bodur, F. (1990). "Fotoğrafın Gazetelerde Kullanılmasının Gerekliliği ve Basın Fotoğrafçılığı". Kurgu Dergisi, (7), 297-303. http://ekurgu.anadolu. edu.tr/assets/upload/pdf/20160513123631_ekurgu.pdf

Briggs, A., Burke, P. (2011). Medyanın Toplumsal Tarihi. (Çev.: Ümit Hüsrev Soysal, Erkan Uzun). Kırmızı Yayınları.

Castells, M. (2003). Ă̆ Toplumunun Yükselişi. (Çev.: Ebru Kılıç). Bilgi Üniversitesi Yayınları.

Castells, M. (2004). Kimliğin Gücü. (Çev.: Ebru Kılıç). İstanbul Bilgi Üniversitesi Yayınları.

Çakır, M. (2014). Görsel Kültür ve Küresel Kitle Kültürü. Ütopya Yayınları.

Dora, S. (2003). Büyüyen Fotoğraf Küçülen Sosyoloji. Babil Yayınları.

Duncum, P. (2005). Visual Culture Art Education: Why, What and How? (Ed. Richard Hickman). Critical Studies in Art \& Design Education. Intellect Books.

Freund, G. (2006). Fotoğraf ve Toplum. (Çev.: Şule Demirkol). Sel Yayıncılık.

Henderson, K. (1999). On Line And On Paper: Visual Representations, Visual Culture, And Computer Graphics In Design Engineering. Cambridge: MIT Press. Erişim Tarihi: 16.11.2016 http://www.jstor.org

Jenks, C. (1995). Visual Culture. Routledge.

Lester, P., M. (1995). Visual Communication. Wadsworth Publishing Company

Mirzoeff, N. (1998). “What Is Visual Culture?”. Mirzoef, N. (Ed). The Visual Culture Reader in (ss 3-13). Routledge.

Mirzoeff, N. (1999). An Introduction to Visual Culture. Routledge. Ong 2012

Mitchell, J, M. (1994). Picture Theory. The University of Chicago Press.

Mitchell, W. J. T. (1995). “What Is Visual Culture?” Lavin, I. (Ed.). Meaning In The Visual Arts: Views From The Outside in (ss.207-217). Princeton: Institute For Advanced Study.

Oskay, Ü. (2000). XIX. Yüzyıldan Günümüze Kitle Illetişiminin Kültürel Işslevleri. Der Yayınları.

Özdemir, S., Karalar, H. (2012).” Günümüz Teknolojileri Ne Kadar Ak1llı?” Türkiye Bilişim Derneği Bilişim Dergisi. Sayı: $146 . \quad$ 100-107. http://www.bilisimdergisi.org.tr/s146/pdf/100-107.pdf

Paglia, C. (2014). Cinsel Kimlikler. (Çev.: Anahid Hazaryan, Fikriye Demirci). Epos Yayınlar1. 
Postman, N. (2010). Televizyon Öldüren Eğlence. (Çev. Osman Akınhay). Ayrıntı Yayınları.

Tavin, K. M.Ve Housman, J. (2004): “Art Education And Visual Culture in the Age Of Globalization”, Art Education, 57 (5). https://www.jstor.org/stable/3194104

Turan, Ergün. (2011). "Fotoğraf: Belleği Olan Ayna". Sanat- Tasarım Dergisi. Cilt:1(2), 19-24. http://e-dergi.marmara.edu.tr/marustd/index

Walter J.Ong, (1999). Sözlü ve Yazılı Kültür. (Çev.: Sema Postacıŏlu Banon), Metis Yayınları.

Williams, R. (2003). Televizyon, Teknoloji ve Kültürel Biçim. (Çev.: Ahmet Ulvi Türkbağ). Dost Kitabevi. 